\title{
Assessment of Vitamin D deficiency among older adult patients with an orthopaedic fracture and its association with increasing age
}

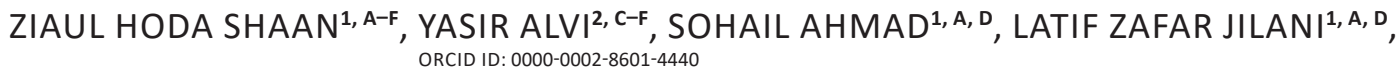

MOHD. FAIZAN ${ }^{1, D, E}$, ZIKKI HASAN FATIMA ${ }^{3, B, C, E}$

${ }^{1}$ Department of Orthopaedics, Jawaharlal Nehru Medical College \& Hospital, Aligarh Muslim University (AMU), Aligarh, India

${ }^{2}$ Department of Community Medicine, Jawaharlal Nehru Medical College \& Hospital, Aligarh Muslim University (AMU), Aligarh, India

${ }^{3}$ Department of Pathology, Jawaharlal Nehru Medical College \& Hospital, Aligarh Muslim University (AMU), Aligarh, India

A - Study Design, B - Data Collection, C - Statistical Analysis, D - Data Interpretation, E - Manuscript Preparation, F - Literature Search, G - Funds Collection

Summary Background. Orthopaedic fractures are one of the common presentations among elderly patients at any primary care facility. While most researches have labelled osteoporosis as being responsible for these fractures in the elderly, vitamin D deficiency, despite being prevalent in all races, age groups and ethnic backgrounds, is given lesser importance.

Objectives. To assess vitamin D level and its relation with advancing age among older adults presenting with an orthopedic fracture. Material and methods. A cross-sectional study was performed at one of the orthopaedic OPD, in tertiary care hospital from North India. The patients 45 years and above presenting with orthopaedic fracture were eligible and out of whom 102 were included in the study. For assessing vitamin D level, we measured serum $25(\mathrm{OH}) \mathrm{D}$ level, taking cut-off for deficiency, insufficiency and normal levels at $<10,10-29$ and $30 \mathrm{ng} / \mathrm{ml}$ or more respectively.

Results. Out of 102 elderly patients we selected, $59 \%$ were male and $41 \%$ were females, with the mean age of $61 \pm 13.4$ years. Majority of them (94.2\%) had low serum vitamin D levels. We observed lower levels of vitamin D level to be significantly associated with higher age, menopausal females and no sunlight exposure.

Conclusions. With almost all older patients with fracture had low vitamin D levels and its high association with advancing age, we recommend to screen all people for vitamin D deficiency, starting middle age and proper management to prevent fracture in elderly. Key words: vitamin D deficiency, aged, fractures, bone, risk factors.

Shaan ZH, Alvi Y, Ahmad S, Jilani LZ, Faizan M, Fatima ZH. Assessment of Vitamin D deficiency among older adult patients with an orthopaedic fracture and its association with increasing age. Fam Med Prim Care Rev 2019; 21(4): 372-376, doi: https://doi.org/10.5114/ fmpcr.2019.90171.

\section{Background}

As the population ages, patients with various chronic diseases and impairments tend to burden primary care facilities. At the same time, primary care for this elderly population has become increasingly complex due to co-morbidities. With relative decreased nutrient intake and impending osteoporosis, the presentation of an orthopaedic fracture at these centres is higher than ever. Orthopaedic or trivial fractures occur as a result of minimal or no trauma. While most of research has labelled osteoporosis as being responsible for these fractures in the elderly [1], vitamin $D$, which is very important for musculoskeletal health, as well as overall well-being, is given lesser importance. Apart from rickets in children and osteomalacia in adults, vitamin $D$ deficiency has been associated with pain and muscle weakness [2-4]. Inadequate serum vitamin $D$ is also associated with secondary hyperparathyroidism - leading to increased bone turnover and bone loss - resulting in increased risk of fractures, especially in the elderly and postmenopausal women, even with minimal trauma [4-6]. Moreover, studies have documented the benefits of vitamin $D$ supplementation in fracture reduction [7], as well as in fracture healing [8], while mixed results were obtained in a recent report by the Royal Osteoporosis Society [4].

Sources of vitamin D in the human body include diet and sunlight. Most North Indians are vegetarian, either because of their faith or due to affordability. Thus, the diet of the general population is often lacking fish and animal protein, which are important sources of vitamin D. Because of affordability, none of the food products available in the market - unlike western countries - are fortified with vitamin D or even calcium. This is further complicated by a few food toxins, like phytates, which are common in a vegetarian diet, preventing the absorption of calcium from the gut and thus disbalancing the vitamin D-calcium homeostasis in the body [9]. Studies among the Caucasian population have proposed that 10 minutes of exposure to sunlight overhead and on the arms three times a week would be adequate to prevent vitamin D deficiency [5], although the same cannot be said in reference to the Indian population, where most of the people are brown, having more melanin, which prevents the reaction of UV rays in sunlight with the vitamin D precursor in the skin. Studies in Indian settings have documented larger contact period for the successful reaction [6]. 
While South Asia is considered as one of the most deficient regions, studies from India have documented an even higher prevalence, ranging from 50-91\% distributed among different populations and age groups [9-14]. The elderly population is especially at higher risk of vitamin $D$ deficiency $[5,12]$. This may be attributed to the fact that in old age, the skin and gut are less efficient in producing and absorbing vitamin D, respectively, while immobility among this population decrease the chances of going outdoors and exposure to sunlight [5]. Studies assessing the role of vitamin $D$ as a cause of fractures among the elderly and in the general population is lacking in India, barring a handful of studies among postmenopausal women [15]. Given the importance of vitamin $D$ in overall wellbeing, as well as for musculoskeletal strength, data enlightening the prevalence of vitamin D deficiency in elderly patients could be of great value for policy makers and family physicians.

\section{Objectives}

The present study was conducted to assess Vitamin D deficiency among older adults with an orthopaedic fracture and to identify its relationship with increasing age.

\section{Material and methods}

\section{Study design and setting}

A cross-sectional study was conducted over a period of 12 months from January to December 2015 in Aligarh city, India (27.90 latitude, 78.07 longitude). The patients were selected from the Orthopaedic Out Patient Department, JN Medical College, Aligarh, India. Incidentally, Aligarh is one of the highly populated districts of the state of Uttar Pradesh, which in itself is the most populated state of the country, being the $5^{\text {th }}$ highest populated place in the world, when treated as a country [16]. The Aligarh district, being a part of North India, receives daily sunlight for more than 10 hours throughout the year. The skin complexion of the population is brown in colour. Most of the rural population is involved in agriculture and are exposed to long durations of sunlight with minimal clothing.

\section{Study population}

All patients presenting with trivial fractures to the hip and wrist to the Orthopaedic OPD, JN Medical College, Aligarh, India were eligible for the study. During the study period, we aimed to study 100 patients aged 45 years or more presenting with a trivial fracture. A trivial fracture may be defined as one that occurs as a result of minimal trauma, such as a fall from a standing or sitting position or one that occurs without any identifiable trauma. Patients with abnormal kidney function, abnormal thyroid function, liver disease, history of oesophageal disease, peptic ulcer or cancer or those taking long-term therapy, like oestrogen replacement therapy/corticosteroids/anticonvulsants/ /anticoagulants/glucocorticoid, were excluded from the study.

\section{Study instruments and assessment of vitamin D status}

A pre-designed questionnaire covering various risk factors was used to collect data. All study subjects were administered a questionnaire illustrating a detailed history, followed by a physical examination. For estimation of vitamin $D$ levels, we measured pro-hormone 25-hydroxyvitamin $D(25(\mathrm{OH}) \mathrm{D})$ rather than the measurement of serum $1,25(\mathrm{OH})_{2} \mathrm{D}$ concentrations, as the former is considered a better assessment of vitamin $D$ deficiency [4]. After gaining consent from the patients, a blood sample $(4 \mathrm{ml})$ was collected in ice-cooled syringes $\left(0-4^{\circ} \mathrm{C}\right)$, maintaining a proper cold chain, while sending samples to the endocrinology lab (within 1-2 hours). Before being subjected to a hormonal assay, the samples were centrifugated at 1,200 rpm for 10 minutes, followed by collection of the serum from the top of the vial. We performed a direct competitive chemiluminescence immunoassay (CLIA) for quantitative determination of total serum 25(OH)D. During this, a light signal is measured by a photomultiplier in relative light units (RLU), which is inversely proportional to the concentration of $25(\mathrm{OH}) \mathrm{D}$ present in the calibrators, controls or samples. The operating instructions for the test were strictly adhered to, ensuring accurate measurement of the $25(\mathrm{OH}) \mathrm{D}$ in the samples.

\section{Definitions}

Assessment of vitamin D status is based on the measurement of serum 25(OH)D. While there is no generalised consensus on optimal levels of serum 25(OH)D for deficiency and insufficiency, most researchers consider more than $30 \mathrm{ng} / \mathrm{ml}$ as a sufficient level $[6,9,17]$. Lips classified vitamin D deficiency at a level of less than $20 \mathrm{ng} / \mathrm{ml}$ among Caucasian, but at the same time, they stressed that the cut-off for these levels should be based on population studies and the level which triggers secondary hyperparathyroidism [5, 18]. The Royal Osteoporosis Society uses a more stringent cut-off of deficiency at less than $10 \mathrm{ng} / \mathrm{mL}$ [4]. For our study, we observed the following classification:
1) deficiency: $<10 \mathrm{ng} / \mathrm{mL}$,
2) insufficiency: $10-29 \mathrm{ng} / \mathrm{mL}$,
3) sufficiency: $30-100 \mathrm{ng} / \mathrm{mL}$.

\section{Data management and statistics}

Statistical analysis was performed using the Statistical Package for Social Sciences (SPSS) Version 20 [19]. The categorical variables were represented as percentage (\%) along with a $95 \%$ confidence interval, and continuous variables were expressed as a mean with standard deviation. The statistical significance was tested by either correlation analysis between two continuous variables or by unpaired $T$ tests for independence, as well as the Analysis of Variance (ANOVA), wherever applicable, with the Bonferroni test for post-hoc assessments to identify groups that are homogenous with respect to mean. All tests were two tailed, and a $p$-value of $\leq 0.05$ was considered significant.

\section{Ethical consideration}

The study was approved by the board of studies and the Institutional Ethics and Research Advisory Committee, JN Medical College, AMU, Aligarh. Informed consent was obtained from each participant prior to the study. Appropriate health education and adequate counselling was provided to all the patients.

\section{Results}

\section{Socio-demographic and clinical characteri- stics}

During the study period, we included 102 patients in the study, 2 more than what we aimed to include. Out of them, 60 patients $(58.8 \%)$ were male, while the remaining $42(41.2 \%)$ were female. The mean age of the patients was $60.8 \pm 13.4$ years, ranging from 45 to 92 years, with the mean age of males being $60.1 \pm 13.7$ years, while that of females was $61.6 \pm 13.1$ years. Among them, $54.9 \%$ were urban residents, while $45.1 \%$ were living in rural area. The majority of the population was married (83.3\%) and Muslim by religion (59.8\%). None of the participants had ever used sunscreen. Among the presenting complaints, 34 patients presented with intertrochanteric fractures, 66 with fracture neck of the femur, while only 2 patients 
presented with a Colle's fracture. None of the patients were investigated for vitamin $\mathrm{D}$ level or had received treatment for osteoporosis in the past.

\section{Prevalence}

In our study population, the mean level of serum $25(\mathrm{OH}) \mathrm{D}$ was $15.82 \pm 5.88 \mathrm{ng} / \mathrm{mL}$. Out of 102 cases included in the study only $6(5.8 \%)$ patients were in the sufficient range $(>30 \mathrm{ng} / \mathrm{mL})$, while the remaining $94.2 \%$ were classified as either at a deficient or insufficient level. 80 patients (78.4\%) were insufficient (between $10-30 \mathrm{ng} / \mathrm{mL}$ ), and 16 patients (15.6\%) were deficient in serum $25(\mathrm{OH}) \mathrm{D}(<10 \mathrm{ng} / \mathrm{mL})$. Thus, $94.2 \%$ of the patients were classified as having a low level of vitamin D (Table 1 and Figure 1).

\begin{tabular}{|l|l|l|l|}
\hline \multicolumn{4}{|l|}{ Table 1. Status of vitamin D levels in the study population } \\
\hline $\begin{array}{l}\text { Serum Vitamin D } \\
\text { status }\end{array}$ & Frequency & $\%$ & $95 \% \mathrm{Cl}$ \\
\hline $\begin{array}{l}\text { Deficiency } \\
\text { (<10 ng/mL) }\end{array}$ & 16 & 15.7 & $9.8-24.1$ \\
\hline $\begin{array}{l}\text { Insufficiency } \\
(10-29 \mathrm{ng} / \mathrm{mL})\end{array}$ & 80 & 78.4 & $69.4-85.4$ \\
\hline $\begin{array}{l}\text { Sufficiency } \\
(30-100 \mathrm{ng} / \mathrm{mL})\end{array}$ & 6 & 5.9 & $2.5-12.5$ \\
\hline$<20 \mathrm{ng} / \mathrm{mL} *$ & 77 & 75.5 & $66.3-82.7$ \\
\hline$<12 \mathrm{ng} / \mathrm{mL}^{\#}$ & 35 & 34.3 & $25.8-44.0$ \\
\hline
\end{tabular}

* Deficient according to Lips [4], " deficient according to the National Osteoporosis Society.

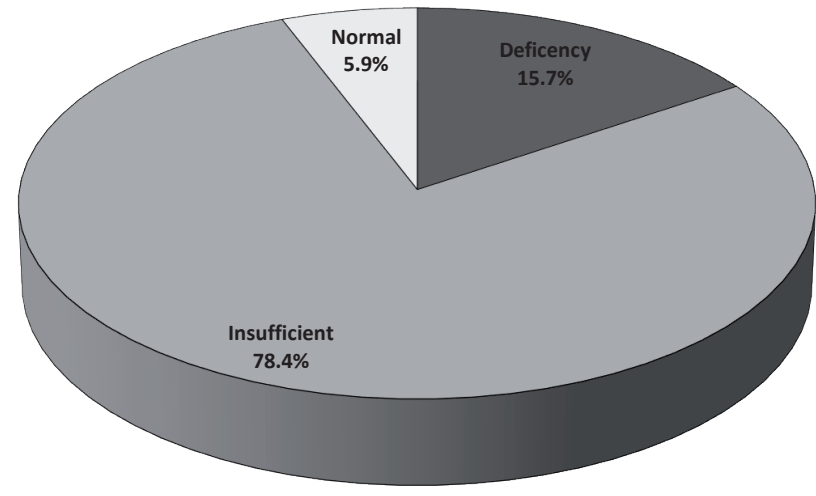

Figure 1. Distribution of patients according to vitamin D status

\section{Associated factors}

To find out the effect of age and vitamin D levels, first we analysed the correlation of age with vitamin $D$ levels and found that they are highly and negatively correlated $(r=-0.641, p<$ 0.001). We also analysed the effect of age on vitamin D status, taking it as a dependent variable and the age of the patients as an independent variable. We found that the mean age in the deficient group $(72.9 \pm 8.9)$ was higher than the insufficient group $(59.4 \pm 12.9)$ and the normal group $(45.8 \pm 2.0)$, and this was statistically significant $(F=13.352, d f 2, p<0.001)$. On post-hoc analysis using the Bonferroni test, a significant difference was found between the mean age of the deficient group and the insufficient group (mean difference $=13.5, p<0.001$ ), the deficient group and the normal group (mean difference $=27.1$, $p<0.001)$, as well as the insufficient group and the normal group (mean difference $=13.6, p=0.026$ ). Thus, a higher age was significantly associated with vitamin $D$ deficiency, as well as insufficiency levels (Table 2 and Figure 2).
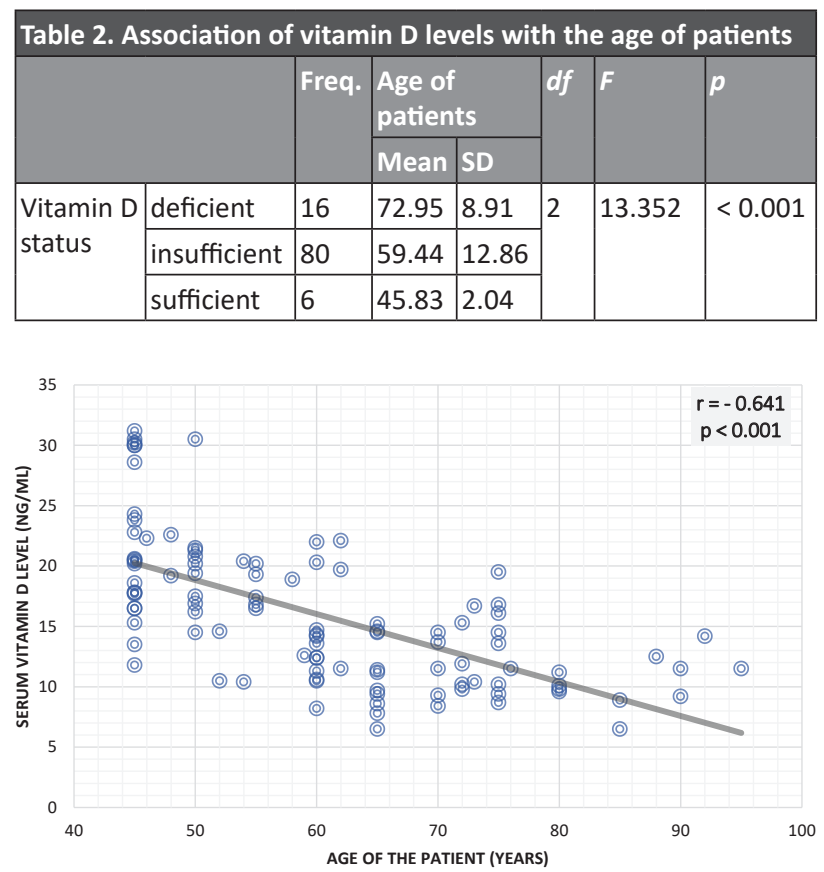

Figure 2. Relationship of age of patients and serum vitamin D levels

In our study population, males had a higher mean of vitamin D level $(17.43 \pm 6.39)$ compared to females $(13.50 \pm 4.14)$, and this was found to be statistically significant $(t=3.766, d f=$ $99.492, p<0.001$ ). When the presence of menopause among females and vitamin D levels were analysed, it was found that females who had not reached menopause had a significantly higher mean of vitamin $D$ level $(17.41 \pm 3.22)$ than those who had reached menopause $(12.58 \pm 3.81)(t=3.311, d f=40$, $p=0.002$ ). Thus, females, especially those who have reached menopause, were found to be significantly associated with lower vitamin $D$ levels (Table 3 ). When we compared the religion and residence of patients with vitamin D levels, we did not find any significant relationship. The patients who reported a history of daily sunlight exposure of $15 \mathrm{~min}$ or more had higher vitamin $D$ levels $(16.45 \pm 6.06)$ in comparison to those who did not $(12.60 \pm 3.55)$, and this difference was statistically significant $(t=-3.8471, d f=37.599, p=0.001$ ) (Table 3).

\begin{tabular}{|c|c|c|c|c|c|c|c|}
\hline \multicolumn{2}{|l|}{ Variables } & \multirow{3}{*}{$\begin{array}{l}\text { Freq. } \\
60 \\
\end{array}$} & \multicolumn{2}{|c|}{ Vitamin D level } & \multirow{3}{*}{\begin{tabular}{|l|}
$t$ \\
3.766 \\
\end{tabular}} & \multirow{3}{*}{\begin{tabular}{|l|}
$d f$ \\
99.5 \\
\end{tabular}} & \multirow{3}{*}{\begin{tabular}{|l|}
$p$ \\
$<0.001$ \\
\end{tabular}} \\
\hline & & & \multirow{2}{*}{$\frac{\text { Mean }}{17.43}$} & \multirow{2}{*}{\begin{tabular}{|l|} 
SD \\
6.39 \\
\end{tabular}} & & & \\
\hline Gender & male & & & & & & \\
\hline & female & 42 & 13.50 & 4.14 & & & \\
\hline \multirow[t]{2}{*}{ Menopause } & not attained & 8 & 17.41 & 3.22 & 3.311 & 40 & 0.002 \\
\hline & attained & 34 & 12.58 & 3.81 & & & \\
\hline \multirow[t]{2}{*}{ Religion } & Hindu & 41 & 16.84 & 4.87 & 1.461 & 98.5 & 0.126 \\
\hline & Muslim & 61 & 15.11 & 6.42 & & & \\
\hline
\end{tabular}




\begin{tabular}{|c|c|c|c|c|c|c|c|}
\hline \multirow{2}{*}{\multicolumn{2}{|c|}{ Variables }} & \multirow[t]{2}{*}{ Freq. } & \multicolumn{2}{|c|}{ Vitamin D level } & \multirow[t]{2}{*}{$t$} & \multirow[t]{2}{*}{$d f$} & \multirow[t]{2}{*}{$p$} \\
\hline & & & Mean & SD & & & \\
\hline \multirow[t]{2}{*}{ Residence } & rural & 46 & 16.43 & 5.60 & 0.962 & 100 & 0.338 \\
\hline & urban & 56 & 15.30 & 6.11 & & & \\
\hline \multirow{2}{*}{$\begin{array}{l}\text { Exposure to sunlight } \\
\text { (<15 min/day) }\end{array}$} & inadequate & 17 & 12.60 & 3.55 & -3.550 & 37.6 & 0.001 \\
\hline & adequate & 85 & 16.45 & 6.06 & & & \\
\hline
\end{tabular}

\section{Discussion}

We observed a very high prevalence $(94.1 \%)$ of hypovitaminosis $D$, with insufficiency among $78.4 \%$ and deficiency among $15.6 \%$ of the cases. Although most epidemiological research on fracture patients are from western countries, our findings replicate these studies, exposing low serum $25(\mathrm{OH}) \mathrm{D}$ concentrations among the elderly population with fractures. Studies have reported the prevalence of hypovitaminosis $D(<30 \mathrm{ng} / \mathrm{mL})$ among fracture patients to be on a lower side, with $89 \%$ in Germany [20], $94 \%$ in Brazil [21], $97 \%$ in the US [22] and up to $100 \%$ in Russia [23]. A study from Poland observed this among $85 \%$ of elderly patients without fractures [24]. A few Indian studies among hip fracture patients found the prevalence of vitamin D deficiency (taken as $<20 \mathrm{ng} / \mathrm{mL}$ ) ranging between $74 \%$ to $76.7 \%[11,15]$, similar to our study finding $(75.5 \%$, at $<20 \mathrm{ng} / \mathrm{mL})$. A study from South India among patients presenting with an orthopaedic trauma also found hypovitaminosis at a level of $95 \%$ [10]. We also conducted a comparative analysis of the serum vitamin $D$ level of our study participants with levels among various populations and settings in India, as presented in the review article [6]. We found that mean vitamin $D$ levels were lower in our elderly patients with fractures in comparison to the general population. These studies, as well as our findings, bring us to the conclusion that hypovitaminosis is a major reason behind trivial trauma resulting in a fracture, which needs to be further studied in a larger multicentric study.

Studies have shown that when serum $25(\mathrm{OH}) \mathrm{D}$ levels fall below $30 \mathrm{ng} / \mathrm{mL}$, calcium absorption decreases, and this leads to secondary hyperparathyroidism, resulting in resorption of the calcium from bone in order to maintain serum calcium within a normal range [6]. This secondary hyperparathyroidism may lead to weak and fragile bones, and subsequently to fractures from trivial trauma. This is the same reason why studies have recognised serum $25(\mathrm{OH}) \mathrm{D}<30 \mathrm{ng} / \mathrm{mL}$ as the cut-off value for vitamin $D$ insufficiency $[5,6]$. More than $90 \%$ of fractures occur as a result of a fall, and the likelihood of falls rises with age as muscle strength and function decrease [25]. Vitamin D supplements, specially along with calcium, would help in resisting fractures, not only by strengthening the bone to survive a trivial fall, but also in averting the chances of falls by strengthening the proximal muscles $[7,26]$. A few studies have also documented the role of vitamin D supplements in the healing of fractures [8]. Thus, we were in consensus that oral vitamin D supplements would be beneficial to all elderly Indians with or without a fracture at presentation.

We observed significantly lower levels of vitamin D with advancing age, among females, especially those who have reached menopause, and among those with inadequate exposure to sunlight. Studies have documented elderly and postmenopausal women as a risk factor for fractures, and supplementation of vitamin $D$ to this group decreases the risk of fractures $[5,7]$. Our study depicts a strong negative association between the advancing age of fracture patients and serum vitamin $D$ levels, supporting the findings of prior studies [13]; while Marwaha et al., in their study among healthy adults, did not find any rela- tion [12]. Although few studies found cases of hypovitaminosis irrespective of gender, the majority were of the notion that this is more common among menopausal females $[12,17]$. Females, especially from the north Indian population, by virtue of various customs and culture, often stay at home, and if they go outside, they are fully or maximally covered, decreasing the chance of exposure to sunlight. The application of sunscreen - which is common among females - may also reduce the chances of adequate penetration of UV rays to the skin, although none of our participants reported a history of ever using sunscreen. India is located between the 8.4 and $37.61 \mathrm{~N}$ latitude, which receives ample sunlight throughout the year. Studies have proposed that at least 30 minutes of exposure to sunlight daily is required for adequate production of vitamin D [6]; although this was even less in our study population. We observed that daily exposure of $15 \mathrm{~min}$ or more of sunlight is significantly associated with a higher level of serum vitamin D. A significant correlation of the degree of exposure to sunlight with vitamin $D$ levels has also been documented by others in India $[13,15]$.

We did not observe residence and religion to have any significant effect on serum vitamin D levels in our study population comprised of older patients with a trivial trauma fracture. Both rural and urban populations, as well as Hindus and Muslims, respectively, had almost similar mean serum vitamin D levels, although all were in the insufficient range, confirming the wide prevalence of vitamin $D$ deficiency among various socioeconomic groups, different ethnicities, rural or urban areas and different professions, as others have measured [6]. Therefore, all elderly people, irrespective of their ethnicity, residence or professions, need to be monitored for hypovitaminosis $D$.

\section{Conclusions}

We conducted this study to assess the level of vitamin D among elderly patients presenting with fractures after a trivial trauma and to find out its association with advancing age. Our results demonstrated that almost all population with fractures have low vitamin $D$ levels. This prevalence of hypovitaminosis among patients with fractures is quite high when compared to other studies among various population/settings in India, which bring us to the conclusion that low vitamin $D$ levels could be a major risk factor for trivial fractures among the elderly. We also documented a high negative correlation of serum vitamin $D$ levels with increasing age, post-menopause females and inadequate exposure to sunlight. Thus, public health measure for reducing fractures among the elderly population can be sought by increasing serum vitamin $D$ levels, through regular screening and oral vitamin $D$ supplements to the deficient/ /insufficient group, along with counselling for wholesome comprehensive dietary intake and adapting a healthy lifestyle with outdoor activities and increasing exposure to sunlight among all the elderly. Given the high prevalence of vitamin $D$ deficiency among the elderly Indian population with fractures and the potential role of vitamin $D$ in the healing of fractures, we advocate the supplementation of vitamin $D$ in all elderly patients. 


\section{References}

1. Hernlund $\mathrm{E}$, Svedbom A, Ivergård $\mathrm{M}$, et al. Osteoporosis in the European Union: medical management, epidemiology and economic burden. Arch Osteoporos 2013; 8: 136, doi: 10.1007/s11657-013-0136-1.

2. Annweiler C, Schott A-M, Berrut G, et al. Vitamin D and ageing: neurological issues. Neuropsychobiology 2010; 62: 139-150, doi: $10.1159 / 000318570$.

3. Bruyére $\mathrm{O}$, Cavalier E, Souberbielle J-C, et al. Effects of vitamin D in the elderly population: current status and perspectives. Arch Public Health 2014; 72: 32, doi: 10.1186/2049-3258-72-32.

4. Francis $\mathrm{R}$, Aspray $\mathrm{T}$, Fraser $\mathrm{W}$, et al. Vitamin $\mathrm{D}$ and bone health: a practical clinical guideline for patient management. Camerton, Bath: National Osteoporosis Society; 2018.

5. Lips P. Vitamin D deficiency and secondary hyperparathyroidism in the elderly: consequences for bone loss and fractures and therapeutic implications. Endocr Rev 2001; 22: 477-501, doi: 10.1210/edrv.22.4.0437.

6. Harinarayan CV, Joshi SR. Vitamin D status in India - its implications and remedial measures. J Assoc Physicians India 2009; 57: 40-48.

7. Bischoff-Ferrari HA, Willett WC, Wong JB, et al. Prevention of nonvertebral fractures with oral vitamin d and dose dependency. Arch Intern Med 2009; 169: 551, doi: 10.1001/archinternmed.2008.600.

8. Gorter EA, Hamdy NAT, Appelman-Dijkstra NM, et al. The role of vitamin D in human fracture healing: a systematic review of the literature. Bone 2014; 64: 288-297, doi: 10.1016/j.bone.2014.04.026.

9. GR, Gupta A. Vitamin D deficiency in India: prevalence, causalities and interventions. Nutrients 2014; 6: 729-775, doi: 10.3390/ nu6020729.

10. Cherian VM, Gouse M, Albert S, et al. Prevalence of vitamin D deficiency in patients presenting with an orthopaedic trauma at a tertiary centre in South India - implications and protocols for replacement therapy. Malays Orthop J 2015; 9: 21-25, doi: 10.5704/ MOJ.1507.007.

11. Dhanwal DK, Sahoo S, Gautam VK, et al. Hip fracture patients in India have vitamin D deficiency and secondary hyperparathyroidism. Osteoporos Int 2013; 24: 553-557, doi: 10.1007/s00198-012-1993-y.

12. Marwaha RK, Tandon N, Garg MK, et al. Vitamin D status in healthy Indians aged 50 years and above. J Assoc Physicians India 2011; 59: 706-709.

13. Pal CP, Kumar H, Kumar D, et al. Prevalence of vitamin D deficiency in orthopaedic patients - a single centre study. J Clin Orthop Trauma 2016; 7: 143-146, doi: 10.1016/j.jcot.2016.06.009.

14. Beloyartseva $\mathrm{M}$, Mithal $\mathrm{A}$, Kaur $\mathrm{P}$, et al. Widespread vitamin D deficiency among Indian health care professionals. Arch Osteoporos 2012; 7: 187-192, doi: 10.1007/s11657-012-0096-x.

15. Paul TV, Selvan SA, Asha HS, et al. Hypovitaminosis D and other risk factors of femoral neck fracture in south indian postmenopausal women: a pilot study. J Clin Diagn Res 2015; 9: OC19-OC22, doi: 10.7860/JCDR/2015/9444.6131.

16. Alvi Y, Khalique N, Ahmad A, et al. Prevalence of depression among HIV-positive patients treated with antiretrovirals at different stage of infection. HIV AIDS Rev 2018; 17: 243-248, doi: 10.5114/hivar.2018.80255.

17. Looned K, Banerjee A, Landge J, et al. Intergenerational decline in vitamin D Status: a cross-sectional study among medical students and their teachers. Int J Nutr Pharmacol Neurol Dis 2017; 7: 12, doi: 10.4103/2231-0738.199070.

18. Thacher TD, Clarke BL. Vitamin D insufficiency. Mayo Clin Proc 2011; 86: 50-60, doi: 10.4065/mcp.2010.0567.

19. IBM SPSS Statistics for Windows 2011.

20. Maier GS, Seeger JB, Horas K, et al. The prevalence of vitamin D deficiency in patients with vertebral fragility fractures. Bone Joint J 2015; 97-B(1): 89-93, doi: 10.1302/0301-620X.97B1.34558.

21. Lopes JB, Danilevicius CF, Takayama L, et al. Vitamin D insufficiency: a risk factor to vertebral fractures in community-dwelling elderly women. Maturitas 2009; 64: 218-222, doi: 10.1016/j.maturitas.2009.09.020.

22. Simonelli C, Weiss TW, Morancey J, et al. Prevalence of vitamin D inadequacy in a minimal trauma fracture population. Curr Med Res Opin 2005; 21: 1069-1074, doi: 10.1185/030079905X50598.

23. Bakhtiyarova S, Lesnyak O, Kyznesova N, et al. Vitamin D status among patients with hip fracture and elderly control subjects in Yekaterinburg, Russia. Osteoporos Int 2006; 17: 441-446, doi: 10.1007/s00198-005-0006-9.

24. Koziarska-Rościszewska M, Rysz J, Stępień M. High prevalence of vitamin D deficiency and its association with metabolic disorders in elderly patients. Fam Med Prim Care Rev 2017; 19: 372-376, doi: 10.5114/fmpcr.2017.70809.

25. Kamińska MS, Brodowski J, Karakiewicz B. The influence of socio-demographic and environmental factors on the fall rate in geriatric patients in primary health care. Fam Med Prim Care Rev 2017; 2: 139-143, doi: 10.5114/fmpcr.2017.67869.

26. Beaudart $C$, Buckinx $F$, Rabenda $V$, et al. The effects of vitamin $D$ on skeletal muscle strength, muscle mass, and muscle power: a systematic review and meta-analysis of randomized controlled trials. J Clin Endocrinol Metab 2014; 99: 4336-4345, doi: 10.1210/jc.20141742.

Tables: 3

Figures: 2

References: 26

Received: 24.06.2019

Reviewed: 9.07.2019

Accepted: 28.07.2019

Address for correspondence:

Yasir Alvi, MD

Department of Community Medicine

Jawaharlal Nehru Medical College

Aligarh Muslim University

Aligarh

India 202002

Tel.: +919897292825

E-mail: yasiralvi13@gmail.com 